\title{
Estudo de obtenção da membrana cerâmica densa $\mathrm{BaCeO}_{3}$
}

\author{
Study of obtaining dense ceramic \\ membrane $\mathrm{BaCeO}_{3}$
}

Aliciane Cíntia Maia Gama ${ }^{1}$, Angélica Belchior Vital ${ }^{2}$,
André Luís Lopes Moriyama ${ }^{2}$, Carlson Pereira de Souza

\author{
${ }^{1}$ Laboratório de Materiais Nanoestruturados e Reatores Catalíticos - LAMNRC - PPGCEM/NTI/UFRN, CEP: 59078- \\ 970, Natal, Rio Grande do Norte, Brasil. \\ ${ }^{2}$ Laboratório de Materiais Nanoestruturados e Reatores Catalíticos - LAMNRC - PPGEQ/NTI/UFRN, CEP: 59078-970, \\ Natal, Rio Grande do Norte, Brasil. \\ e-mail: aliciane.gama@gmail.com,angelicavital.eq@gmail.com, allmoriyama@eq.ufrn.br, carlson@ufrnet.br
}

\begin{abstract}
RESUMO
Nos últimos anos, pós cerâmicos à base de óxidos de estrutura do tipo perovskita ganharam atenção considerável devido às suas aplicações tecnológicas na área de membranas permeáveis de oxigênio. O óxido misto $\mathrm{BaCeO}_{3}$ apesenta-se como um material amplamente estudado em uma grande diversidade de aplicações, seja como materiais eletrolíticos em células a combustível, ou mesmo como catalisadores nas reações de catálise. Dessa forma, o presente trabalho teve como objetivo sintetizar a fase $\mathrm{BaCeO}_{3}$, pelo método de coprecipitação em meio oxalato, verificando o efeito da sinterização com diferentes aglutinantes na estabilidade térmica e densificação da membrana. A técnica de coprecipitação em meio oxalato mostrou-se eficaz na obtenção da perovskita $\mathrm{BaCeO}_{3}$. As amostras obtidas durante as sínteses foram caracterizadas por difração de raios-x, observando-se a formação da fase ortorrômbica da perovskita $\mathrm{BaCeO}_{3}$. Para determinar o tamanho médio de cristalito foi utilizada a equação de Scherrer e de Williamson Hall, chegando-se a um valor próximo a de 107 nm. Conforme a literatura [1,2] e diante dos resultados apresentados definiu-se como condições favoráveis para formação de material com o menor tamanho de cristalito e maior pureza da fase formada, a amostra de pH 13 e de temperatura de calcinação de $1000^{\circ} \mathrm{C}$. Através da microscopia eletrônica de varredura (MEV) pode-se observar a formação de cristais homogêneos. Por fim, foi possível observar que a sinterização na presença dos aglutinantes parafina e álcool polivinílico a $1300^{\circ} \mathrm{C}$ com patamar de $5 \mathrm{~h}$, permitiu a obtenção de pastilhas densas com bons níveis de retração, possuindo estabilidade térmica ideal para serem utilizadas como membranas permeáveis de oxigênio e como eletrólito de células a combustível.
\end{abstract}

Palavras-chave: $\mathrm{BaCeO}_{3}$; Coprecipitação em meio oxalato; Sinterização; Membrana; Permeação de oxigênio.

\section{ABSTRACT}

In recent years, ceramic powders based on oxides with structure of the perovskite have gained considerable attention due their technological applications in oxygen permeable membranes. The mixed oxide $\mathrm{BaCeO}_{3}$ is introduced as a broadly studied material in a large variety of uses, either as electrolyte materials for fuel cells, or as catalysts in catalysis reactions. Thus, this study had the goal to synthesize the $\mathrm{BaCeO}_{3}$ phase by coprecipitation method amid oxalate, verifying the effect of sintering with different binders in thermal stability and densification of the membrane. The co-precipitation technique in oxalate was effective to obtain the perovskite $\mathrm{BaCeO}_{3}$. The samples obtained during the syntheses were characterized by X-ray diffraction, and it was possible to notice the formation of the orthorhombic phase of perovskite $\mathrm{BaCeO}_{3}$. To stablish the average crystallite size it was used the equation of Scherrer and Williamson Hall, coming to a value close to 107 $\mathrm{nm}$ As the literature [1,2] and against the results defined as favorable conditions for formation of material with the smallest size of crystallite and greater purity of the phase formed the sample $\mathrm{pH} 13$ and calcination temperature of $1000^{\circ} \mathrm{C}$. By scanning electron microscopy (SEM) it could be seen the formation of homogeneous crystals. Finally, it was observed that the sintering in the presence of binders paraffin and polyvinyl alcohol at $1300^{\circ} \mathrm{C}$ allowed the obtaining of dense pellets with good shrinkage levels, having ideal thermal 
stability for use as oxygen permeable membranes and as a fuel cell electrolyte.

Keywords: $\mathrm{BaCeO}_{3}$; Co-precipitation amid oxalate; Sintering; Membrane; Oxygen Permeation.

\section{INTRODUÇÃO}

A grande demanda por elementos terras raras vem se intensificando devido a sua grande aplicabilidade na indústria eletroeletrônica, em veículos movidos a energias alternativas e o incremento em novos mercados, como os de cerâmicas e PVC [3]. Entre os elementos terras raras, o cério pode desempenhar um papel chave em tais aplicações industriais.

As perovskitas do tipo $\mathrm{ABO} 3$ são de especial interesse por apresentarem condutividade elétrica e iônica com excelente estabilidade química em uma ampla faixa de temperatura. Sendo materiais com grande potencial no campo das membranas de separação de gases, sensores ou eletrólitos em pilhas a combustível [4].

Na catálise, diversos trabalhos têm confirmado a multifuncionalidade das perovskitas. Desse modo as perovskitas têm sido aplicadas na oxidação total do etanol [5], na conversão do metano a gás de síntese pela reforma com CO2 [6] e na redução de NO ou hidrogênio para produzir CO2 e N2 [7].

As propriedades de condução de elétrons de amostras simples ou dopados com $\mathrm{BaCeO} 3$ têm sido amplamente investigadas, por apresentarem elevada condutividade de prótons. Em altas temperaturas esses condutores de prótons poderão ser usados em aplicações eletroquímicas como catalizadores de vapor pra produção de hidrogênio, sensores de gás hidrogênio, bombas de hidrogênio e membranas, e como materiais eletrolíticos para células a combustível de óxido sólido de temperatura intermediária $\left(500\right.$ a $\left.750{ }^{\circ} \mathrm{C}\right)$. [8-11]

Como conversor catalítico o Cerato de Bário pode ter utilidade em aplicações automotivas. Quando associado com outros catalizadores o cério presente na estrutura do cerato pode liberar ou absorver oxigênios na corrente de escape de um motor de combustão, podendo então reduzir efetivamente as emissões de NOx, bem como converter $\mathrm{CO}$ prejudicial, para $\mathrm{CO} 2$ menos nocivo ao meio ambiente [12].

Dessa maneira, determinou-se como objeto de estudo deste trabalho a síntese da perovskita $\mathrm{BaCeO} 3$ pela técnica de coprecipitação em meio oxalato, buscando analisar a influência das condições de síntese, na estabilidade térmica e densificação da membrana após a fase de sinterização. A técnica de coprecipitação em meio oxalato foi escolhida devido à possibilidade de obtenção de materiais com maior homogeneidade, menor tamanho de cristalito e maior rendimento.

\section{MATERIAIS E MÉTODOS}

\subsection{Síntese do pó de $\mathrm{BaCeO}_{3}$}

$\mathrm{O}$ material $\mathrm{BaCeO}_{3}$ foi sintetizado através do método de coprecipitação em meio oxalato proposto por SANTOS [13]. O método consiste numa mistura equimolar de íons metálicos referentes ao nitrato de bário e nitrato de cério e de uma solução de ácido oxálico e oxalato de amônio numa razão mássica de (1:1). Para tal, determinou-se a massa do pó desejado e pesaram-se os componentes, solubilizando os cristais em água deionizada com o auxílio de um agitador mecânico. Transferiram-se então as soluções, separadamente, para balões de $500 \mathrm{ml}$, a fim de manter fixo o volume do experimento.

Com as soluções prontas, iniciou-se o experimento propriamente dito, utilizando buretas volumétricas de pistão com vazão automática para gotejá-las simultaneamente no meio reacional com pH básico ( $\mathrm{pH}$ 13) sob agitação mecânica, e uma bureta contendo trietilamina, cuja vazão é controlada de acordo com as variações de pH para mantê-lo no valor desejado.

Após o término do processo de gotejamento, a solução foi transferida para um balão volumétrico completando-se o volume com água deionizada. A solução foi deixada em repouso por um período de aproximadamente $24 \mathrm{~h}$ para que o pó fosse decantado, sendo então realizada uma lavagem e filtração a vácuo, com água deionizada levemente aquecida até que o filtrado alcançasse $\mathrm{pH}$ semelhante ao da água deionizada utilizada na lavagem. Em seguida realizou-se a secagem do filtrado em uma estufa e posteriormente o pó foi submetido a tratamento térmico a $1000^{\circ} \mathrm{C}$ por $5 \mathrm{~h}$ com taxa de aquecimento de $5^{\circ} \mathrm{C} / \mathrm{min}$. 


\subsection{Confecção das pastilhas}

Primeiramente, o pó foi submetido a um processo de cominuição no almofariz de ágata seguido do processo de peneiramento com malha de 200 Mesh. Logo após o peneiramento, o pó foi misturado com aglutinantes (10\% da massa de $\mathrm{BaCeO}_{3}$ utilizado para confecção da pastilha) - acetona, ácido polivinílico e parafina -, a fim de aglutinar a amostra. As amostras foram compactadas utilizando-se uma matriz de aço ferramenta de $10 \mathrm{~mm}$ de diâmetro e aproximadamente $2 \mathrm{~mm}$ de espessura na membrana verde.

As massas de pó calculadas para a compactação foram devidamente pesadas, despejadas sob a matriz e em seguida prensadas uniaxialmente com uma carga de aproximadamente 3 tf, durante 15 min. Mais tarde, as pastilhas foram extraídas cuidadosamente da matriz e levadas ao equipamento de dilatometria.

\section{RESULTADOS E DISCUSSÃO}

\subsection{Análise Termogravimétrica}

Após o processo de síntese do material cerâmico $\mathrm{BaCeO}_{3}$, os pós foram submetidos a análise termogravimétrica. As amostras foram submetidas a análises de TG com taxa de aquecimento igual a $10{ }^{\circ} \mathrm{C} / \mathrm{min}$ partindo da temperatura ambiente até $1100{ }^{\circ} \mathrm{C}$. A Figura 1 apresenta a análise termogravimétrica (TG) do precursor oxalato da fase $\mathrm{BaCeO}_{3}$.

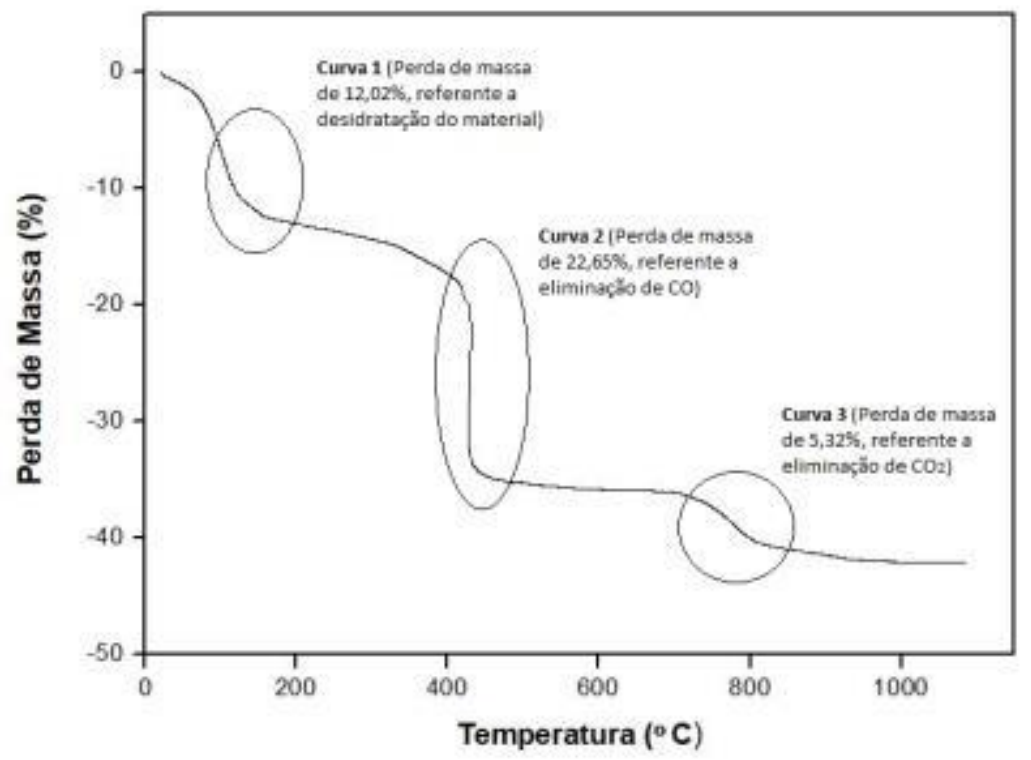

Figura 1: TG do pó precursor $\mathrm{BaCeO}_{3}$.

Interpretando os dados da Figura 1 e realizando associação dos eventos ocorridos com os expostos por CHEN et al. [2] e SANTOS [13], é possível presumir que a amostra de $\mathrm{BaCeO}_{3}$ apresentou três estágios de decomposição térmica. O primeiro estágio (curva 1) se refere à desidratação do material e à decomposição de alguns componentes orgânicos, com uma perda de massa igual a 12,02\%. O próximo estágio (curva 2), é correspondente à segunda etapa de perda de massa, associada à eliminação de $\mathrm{CO}$, com perda de massa igual a $22,65 \%$. O último estágio (curva 3) teve uma perda de massa de 5,32\% e se refere a eliminação do $\mathrm{CO}_{2}$ e formação do óxido misto $\mathrm{BaCeO}_{3}$. Nos resultados apresentados por NASCIMENTO et al. [14] a fase $\mathrm{BaCeO}_{3}$ é reproduzida acima de $900{ }^{\circ} \mathrm{C}$. Todavia, segundo CHEN et al. [2] o produto final de fase pura aparece apenas entre $1020-1050{ }^{\circ} \mathrm{C}$. Diante dessa análise, pode-se considerar que a fase pura da perovskita $\mathrm{BaCeO}_{3}$ não poderá ser obtida em temperaturas de calcinação inferiores a $1000^{\circ} \mathrm{C}$.

Conforme a análise de TG da amostra apresentada verifica-se que a curva termogravimétrica é composta por três etapas distintas de decomposição de material, com uma perda de massa total de cerca de $40 \%$. 


\subsection{Difração de Raios-X}

A Figura 2 apresenta o difratograma de raios-x referente à síntese do material cerâmico na condição de síntese proposta ( $\mathrm{pH} 13)$. A amostra do pó foi calcinada a $1000^{\circ} \mathrm{C}$ por $5 \mathrm{~h}$, conforme os resultados obtidos pela análise termogravimétrica e dados da literatura [2].

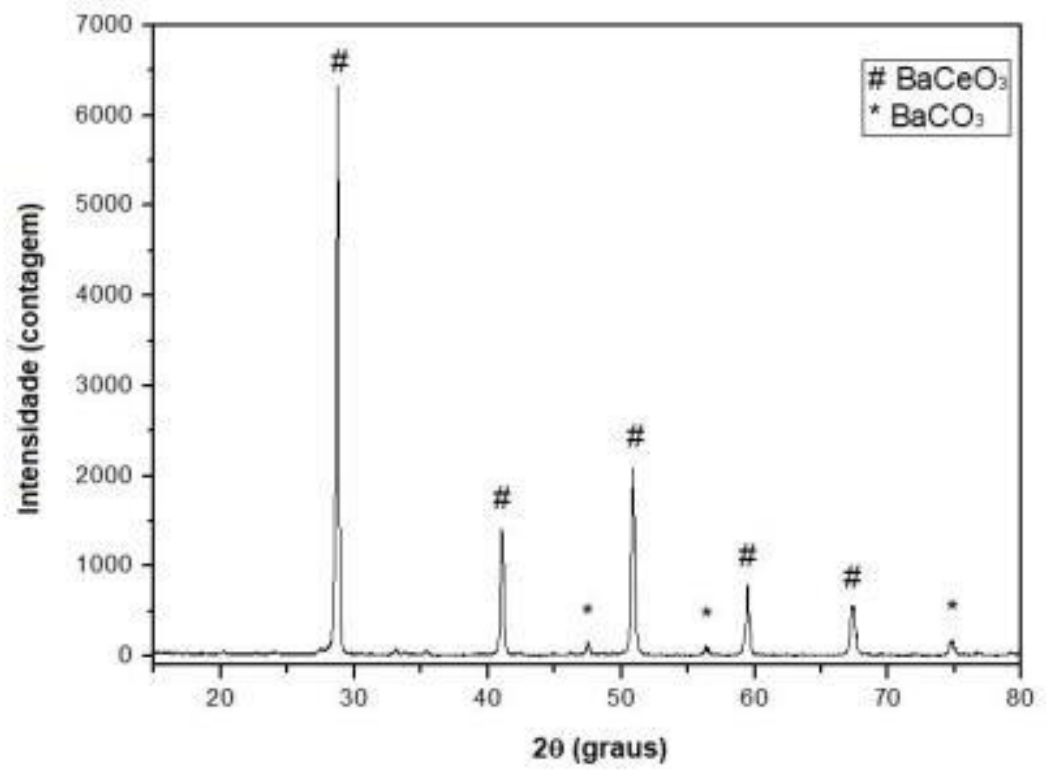

Figura 2: Difratograma de raios-x do $\mathrm{BaCeO}_{3}$ sintetizado pelo método de coprecipitação em meio oxalato.

De acordo com o resultado da difratograma de raios-x apresentado, a fase $\mathrm{BaCeO}_{3}$ foi obtida na condição de síntese adotada. A fase $\mathrm{BaCeO}_{3}$ foi confirmada a partir da carta padrão ICSD - 79001 [15], conforme a figura 3. O difratograma apresentou picos característicos da perovskita $\mathrm{BaCeO}_{3}$, mas com a presença de uma fase secundária identificada como carbonato de bário $\left(\mathrm{BaCO}_{3}\right)$, conforme destacada como impureza $(*)$ na Figura 2. Segundo a literatura, é comum encontrar a presença de fases secundárias como carbonato de bário e óxido de cério quando a calcinação é realizada em temperatura inferior a $1100{ }^{\circ} \mathrm{C}$ [16].

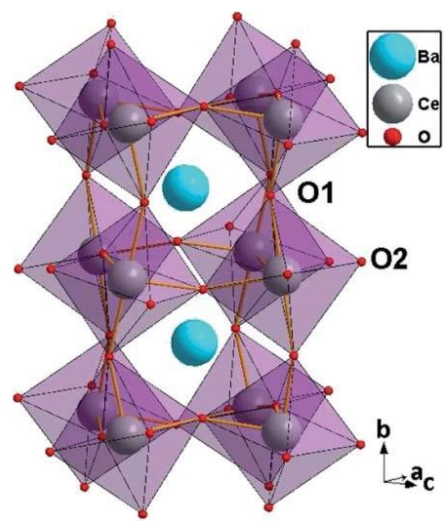

Figura 3: Estrutura ortorrômbica do $\mathrm{BaCeO}_{3}$.

Através do refinamento de Rietveld foi constatado que o material $\mathrm{BaCeO}_{3}$ apresentou sistema cristalino do tipo ortorrômbico com grupo espacial Pmcn, concordante com a literatura [16-21].

Os resultados do difratograma também foram utilizados na determinação do tamanho médio de cristalito a partir da equação de Scherrer (Equação 1). Para o cálculo da microdeformação do cristalito foi utilizada a relação de Williamson-Hall (Equação 2). Os picos utilizados para o cálculo de tamanho de cristalito e microdeformação foram os que tiveram maior intensidade, conforme a Figura 2. 


$$
\begin{aligned}
& D_{h k l}=\frac{k \lambda}{\beta \cos (\theta)} \\
& \frac{\beta x \cos \theta}{\lambda}=\frac{k}{D}+\frac{4 \varepsilon}{\lambda} \operatorname{sen} \theta
\end{aligned}
$$

O tamanho de cristalito $(D)$ e a microdeformação $(\varepsilon)$ do pó de $\mathrm{BaCeO}_{3}$ sintetizado pelo método de coprecipitação em meio oxalato são mostrados na Tabela 1.

Tabela 1: Dados cristalográficos do pó da perovskita $\mathrm{BaCeO}_{3}$ obtidos através das equações de Scherrer e WilliamsonHall.

\begin{tabular}{ccccccc}
\hline TAMANHO DE CRISTALITO & ERRO (\%) & $\begin{array}{c}\text { MICRODEFORMAÇÃO } \\
(\mathbf{n m})\end{array}$ & ERRO (\%) & \multicolumn{3}{c}{ PARÂMETRO DE REDE (nm) } \\
\cline { 5 - 8 } & & E & & a & b & c \\
\hline 107,3 & $\pm 1,5$ & 0,00098 & $\pm 0,0000018$ & 0,87736 & 0,62343 & 0,62135 \\
\hline
\end{tabular}

Conforme os dados apresentados na Tabela 1, o tamanho médio de cristalito é aproximadamente 107,3 $\mathrm{nm}$, na mesma ordem de grandeza que os apresentados por LACORRE et al. [22] e LOBATO [23] et al. quando sintetizados por diferentes métodos de síntese (100 -133 nm).

\subsection{Microscopia Eletrônica de Varredura}

A Figura 4 apresenta as análises de microscopia eletrônica de varredura (MEV) do pó de $\mathrm{BaCeO}_{3}$, calcinados na temperatura de $1000^{\circ} \mathrm{C}$ com patamar de $5 \mathrm{~h}$. As micrografias mostram que o pó possui uma superfície homogênea, com formas arredondadas, mas com certo grau de aglomeração devido ao tamanho de cristalito calculado $(107,3 \mathrm{~nm})$. Na literatura, a perovskita $\mathrm{BaCeO}_{3}$ apresenta uma distribuição homogênea com tamanho médio de cristalino por volta de $100 \mathrm{~nm}$, o que pode ser atribuído as variações do método de síntese, como também do tratamento térmico aplicado.

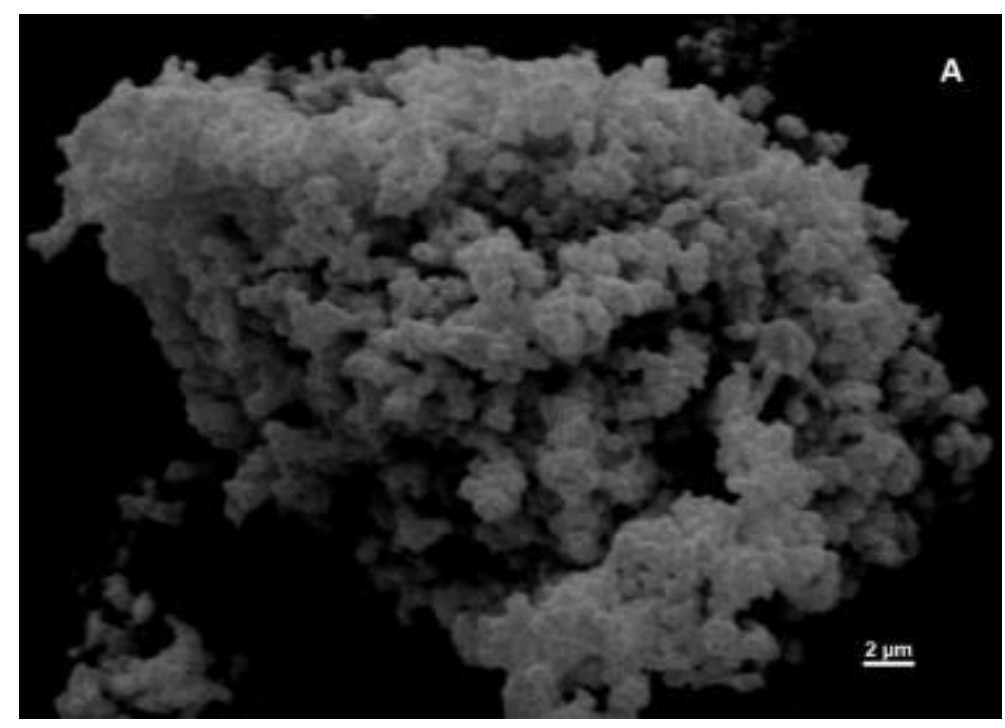




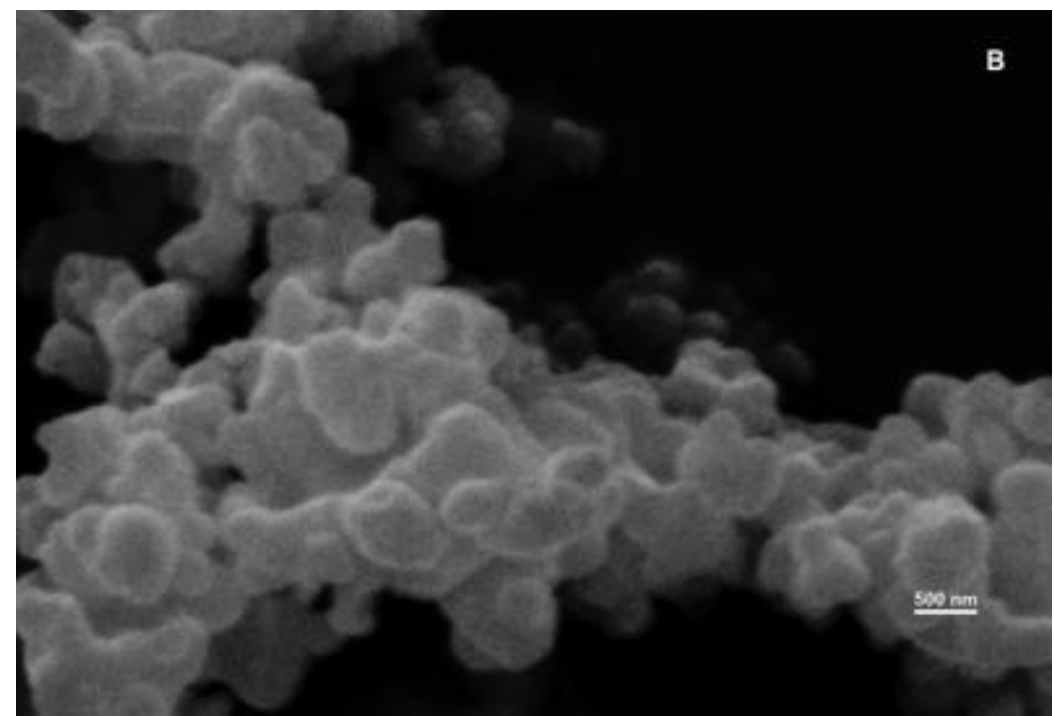

Figura 4: Micrografias, obtidas por microscopia eletrônica de varredura, no modo elétrons secundários, do pó cerâmico $\mathrm{BaCeO}_{3}$. Ampliação de 5000x (A) e 24000x (B).

Estruturas semelhantes foram encontradas nas amostras de LOPES [24] utilizando o método de complexação EDTA-Citrato, onde se observa a mesma forma de aglomeração para pH igual a 10.

Na Figura 5 é mostrado o gráfico obtido através do mapeamento químico por espectroscopia por energia dispersiva (EDS) do pó de $\mathrm{BaCeO}_{3}$. O EDS permite a identificação e mapeamento da distribuição dos elementos químicos contidos no pó de $\mathrm{BaCeO}_{3}$ a partir de mapas composicionais dos elementos desejados. $\mathrm{A}$ partir análise semi-quantitativa da espectroscopia da amostra verifica-se a predominância dos elementos bário e cério em sua composição, demonstrando homogeneidade em sua composição.

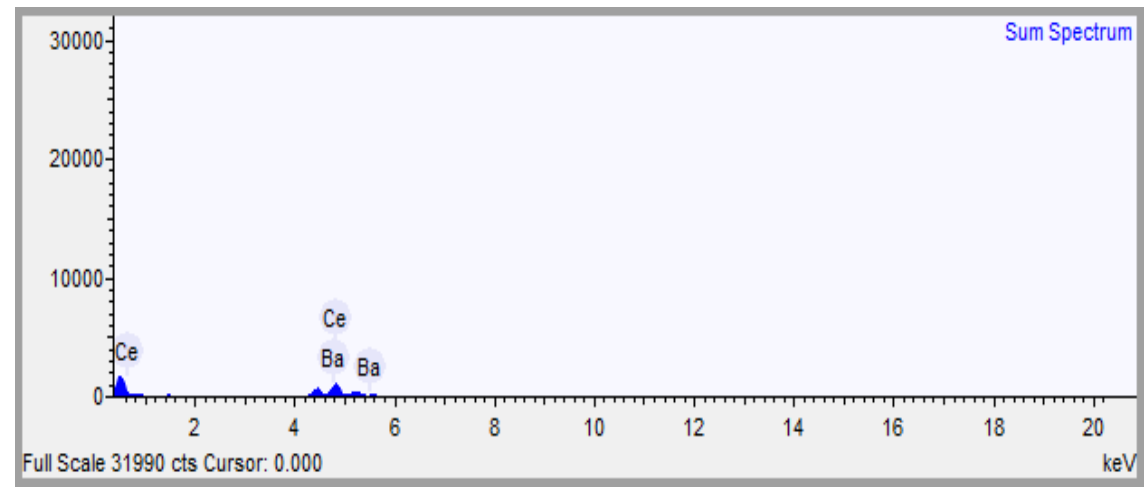

Figura 5: Gráfico do mapeamento químico por EDS do pó $\mathrm{BaCeO}_{3}$.

\subsection{Dilatometria}

Pastilhas de cerato de bário $\left(\mathrm{BaCeO}_{3}\right)$ compactadas com diferentes aglutinantes - acetona [25], parafina [26] e álcool polivinílico [27] - foram sinterizadas com iguais temperaturas $\left(1300{ }^{\circ} \mathrm{C}\right.$ a $\left.5{ }^{\circ} \mathrm{C} / \mathrm{min}\right)$. A utilizaçãode aglutinantes de sinterização capazes de reduzir a temperatura e o tempo de sinterização de diversos compostos cerâmicos, já foi objeto de muitos estudos científicos [28-30]. KOFERSTEIN et al. [20] relata que temperaturas de sinterização acima de $1500{ }^{\circ} \mathrm{C}$ devem ser evitadas, pois os sinterizados de $\mathrm{BaCeO}_{3}$ fundem a aproximadamente $1480^{\circ} \mathrm{C}$, havendo formação de fases secundárias, como o óxido de bário $(\mathrm{BaO})$ e o óxido de cério $\left(\mathrm{CeO}_{2}\right)$.

Objetivando entender o mecanismo de atuação dos aglutinantes no processo de sinterização do cerato de bário $\left(\mathrm{BaCeO}_{3}\right)$, inicialmente, investigou-se a pastilha sem acréscimo de aglutinante. Todavia, a pastilha sem adição de aglutinante não alcançou um nível de compactação desejável para que a análise de dilatometria fosse feito. Desse modo, investigou-se apenas as pastilhas com adição de aglutinantes, a começar pelo aglutinante acetona, como mostra a Figura 6. 


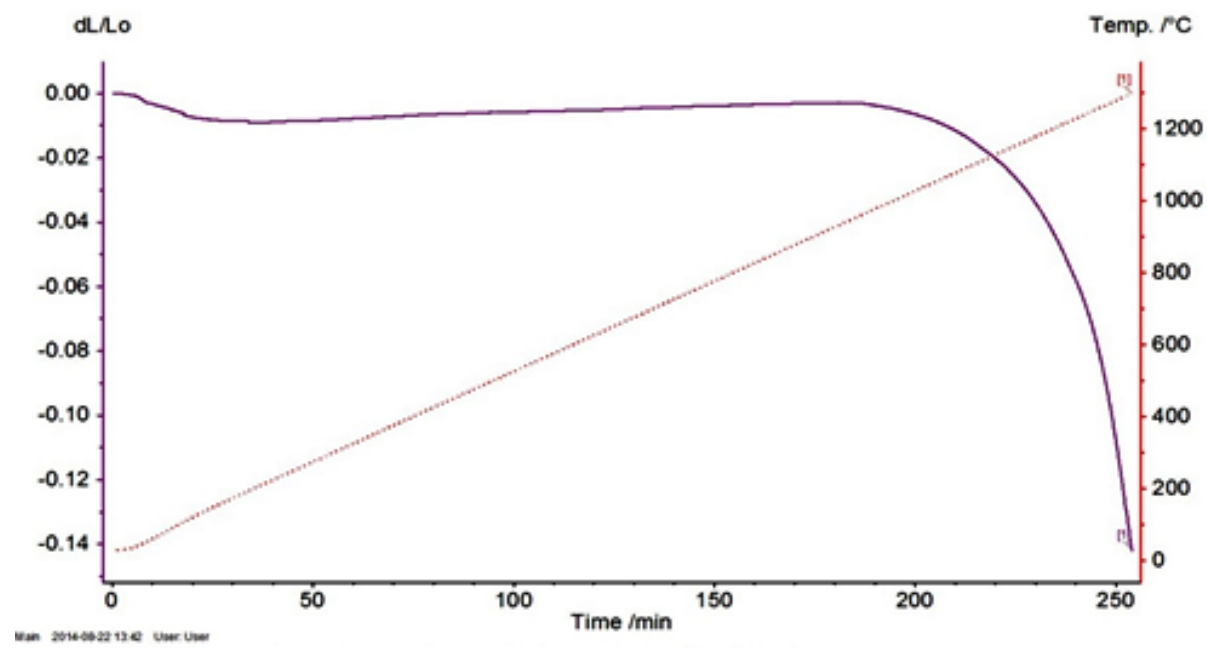

Figura 6: Curva dilatométrica da amostra de $\mathrm{BaCeO}_{3}$ na presença do aglutinante acetona sem tempo de patamar.

A Figura 6 mostra a evolução da retração da pastilha de $\mathrm{BaCeO}_{3}$, na presença do aglutinante acetona, em função do tempo e temperatura de sinterização. Na presença do aglutinante acetona o cerato de bário atingiu retração de aproximadamente $14 \%$, quando sinterizado a $1300{ }^{\circ} \mathrm{C}$, durante $4 \mathrm{~h}$ sem tempo de patamar. $\mathrm{Na}$ temperatura de $100{ }^{\circ} \mathrm{C}$ é observada uma leve retração devida à eliminação da água de umidade. Entre $1200{ }^{\circ} \mathrm{C}$ e $1250{ }^{\circ} \mathrm{C}$ inicia-se o processo de retração, observando-se assim uma mudança na inclinação da curva dilatométrica.

$\mathrm{Na}$ figura 7 é mostrado a curva dilatométrica referente à pastilha de $\mathrm{BaCeO}_{3}$, sinterizada na presença do aglutinante parafina a $1300{ }^{\circ} \mathrm{C}$, durante $9 \mathrm{~h}$ com tempo de patamar de $5 \mathrm{~h}$. Na presença da parafina o $\mathrm{BaCeO}_{3}$ atingiu uma retração próxima a $22 \%$. Na faixa de temperatura de $0{ }^{\circ} \mathrm{C}$ a $100{ }^{\circ} \mathrm{C}$ é observado uma retração significativa $(8 \%)$ devido ao ponto de fusão da parafina (aproximadamente $52{ }^{\circ} \mathrm{C}$ ) e a eliminação da água.

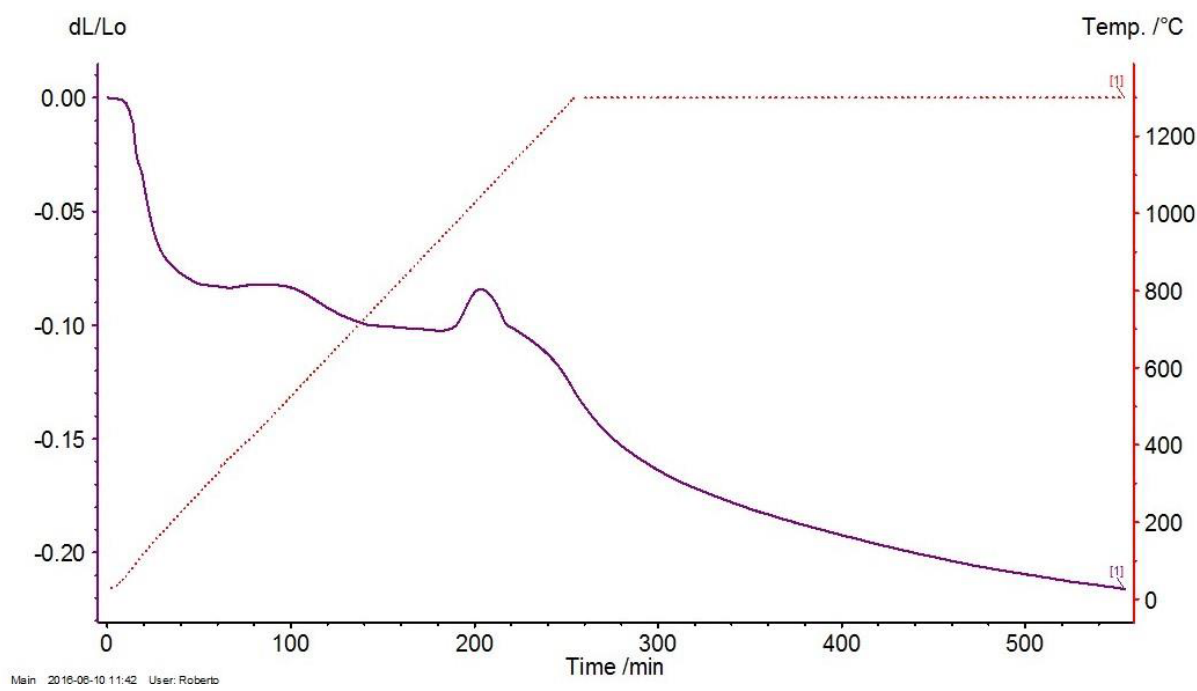

Figura 7: Curva dilatométrica da amostra de $\mathrm{BaCeO}_{3}$, na presença do aglutinante parafina com tempo de patamar de $5 \mathrm{~h}$.

Na figura 7 pode-se visualizar também um perfil de sinterização não usual com um comportamento anômalo de expansão em torno de $800^{\circ} \mathrm{C}$. Acredita-se que essa expansão pode ser atribuída tanto ao rearranjo dos constituintes quanto às reações ocorridas durante o processo de sinterização. A partir da temperatura de $1200{ }^{\circ} \mathrm{C}$, nota-se uma queda brusca, que pode ser atribuída à difusão volumétrica, que é responsável pela retração e densificação da pastilha. Na difusão volumétrica a fase líquida escoa para os interstícios entre as partículas mais refratárias, que não se fundiram, e por capilaridade, provoca a aproximação dessas partículas, 
o que resulta em uma retração bastante significativa.

$\mathrm{Na}$ presença do álcool polivinílico a pastilha de $\mathrm{BaCeO}_{3}$ atingiu retração de $35 \%$, quando sinterizado a $1300{ }^{\circ} \mathrm{C}$, com tempo de patamar de $5 \mathrm{~h}$, conforme Figura 8 .

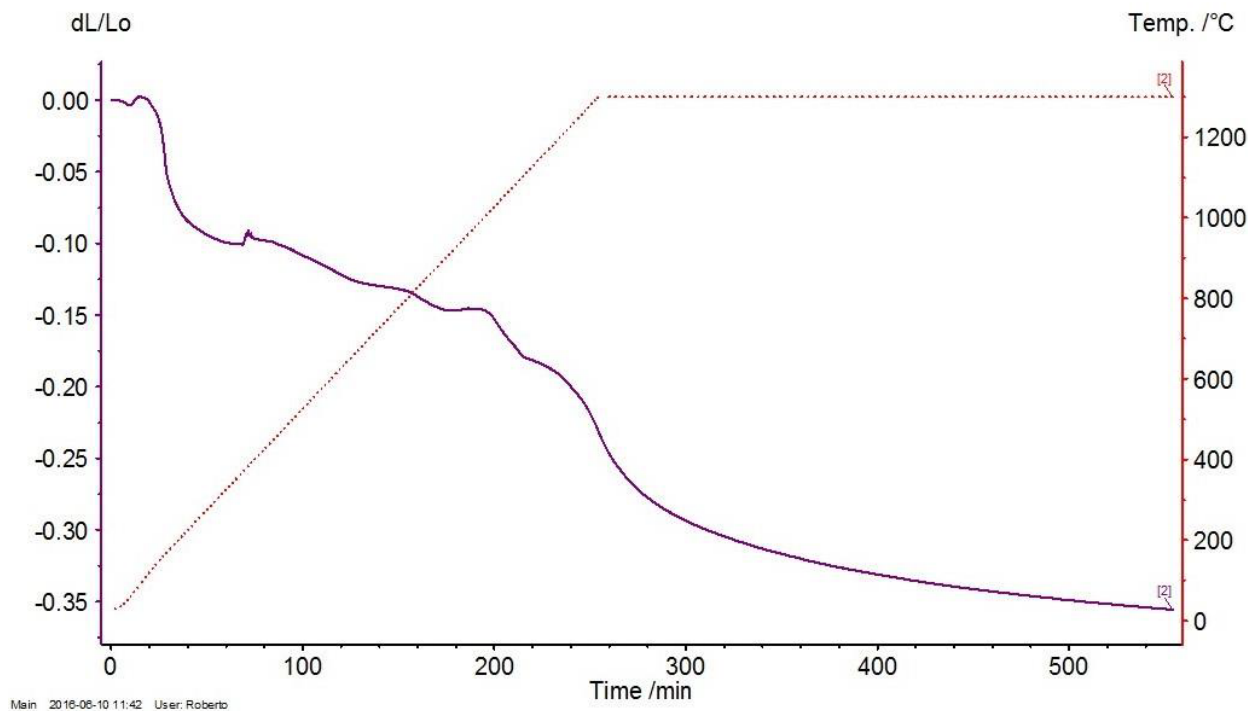

Figura 8: Curva dilatométrica da amostra de $\mathrm{BaCeO}_{3}$, na presença do aglutinante álcool polivinílico com tempo de patamar de 5 h.

Observa-se na figura 8 o mesmo comportamento de retração na faixa de temperatura entre $0{ }^{\circ} \mathrm{C}$ e 200 ${ }^{\circ} \mathrm{C}$, no entanto, a retração se mostra mais intensa, em torno de $10 \%$. A ampliação na faixa de temperatura no que se refere a essa retração, é em razão do ponto de fusão do álcool polivinílico ser maior do que o da parafina (aproximadamente $200{ }^{\circ} \mathrm{C}$ ). Ao contrário do que foi mostrado na Figura 7, a queda brusca na retração da pastilha com álcool polivinílico começa a partir da temperatura de $1100{ }^{\circ} \mathrm{C}$. Isso se deve, principalmente, ao fato de que, o álcool polivinílico por possuir partículas grandes, quando fundido deixa espaços menores no interior da pastilha, minimizando a distância entre as partículas e, consequentemente, proporcionando uma maior retração na pastilha a uma menor temperatura. Ou seja, o álcool polivinílico estaria potencializando a formação da fase líquida, promovendo a antecipação do processo de sinterização, contribuindo dessa forma para a densificação da amostra em temperaturas mais baixas.

\section{CONCLUSÕES}

A partir do difratograma de raios $-\mathrm{x}$ confirmou-se a obtenção da fase $\mathrm{BaCeO}_{3}$ a partir da carta padrão (ICSD - 79001), correspondente a uma estrutura do tipo perovskita ortorrômbica. O tamanho médio de cristalito da perovskita $\mathrm{BaCeO}_{3}$, obtido a partir do difratograma de raios-X e das equações de Sherrer e Williamson-Hall foi de aproximadamente $107,3 \mathrm{~nm}$. Isto é, a perovskita $\mathrm{BaCeO}_{3}$ sintetizada pela rota metodológica proposta apresentou tamanho de cristalito próximos aos encontrados na literatura (160 a $163 \mathrm{~nm}$ ). A morfologia do pó apresentou superfície homogênea, com formas arredondadas, mas com certo grau de aglomeração.

A curva dilatométrica do cerato de bário $\left(\mathrm{BaCeO}_{3}\right)$ na presença do aglutinante acetona atingiu retração em torno de $14 \%$, sem tempo de patamar. No entanto, a presença da acetona como aglutinante não conferiru à pastilha cerâmica características adequadas que favorecessem a sua densificação. Por outro lado, a presença de aglutinantes nas pastilhas de $\mathrm{BaCeO}_{3}$ e um tempo de patamar de $5 \mathrm{~h}$, influenciaram a densificação de forma positiva em todo o intervalo de temperatura, produzindo pastilhas cerâmicas com maior retração (aglutinante parafina $22 \%$ e aglutinante álcool pilivinílico $35 \%$ ), ficando evidente que longos tempos de patamar e a presença de aglutinantes são necessários para se atingir maior retração e densificação das pastilhas. Dessa forma, as pastilhas de cerato de bário contendo os aditivos parafina e álcool polivinílico mostraram características que podem tornar seu uso em aplicações como a permeação de oxigênio do ar e como eletrólito de células a combustível, bastante promissor. 


\section{BIBLIOGRAFIA}

[1] SATO, K., OKAMOTO, G., NAITO, M., et al., "NiO/YSZ nanocomposite particles synthesized via coprecipitation method for electrochemically active Ni/YSZ anode", J. Power Sour, v. 193, n.1, pp. 185-188, Agosto 2009.

[2] CHEN, F., SORENSEN, O.T., MENG, G., et al., "Thermal decomposition $\mathrm{BaC}_{2} \mathrm{O}_{4} \cdot 0.5 \mathrm{H}_{2} \mathrm{O}$ studied by stepwise isothermal analysis and non-isothermal thermogravimetry", J. Therm. Anal. Calorim., v. 53, n.2, pp. 397-410, Julho 1998.

[3] FORMOSO, M., PEREIRA, V., MENEGOTTO, E., et al., Os elementos terras raras e sua importância para o setor mineral do Brasil, $1^{a}$ ed., Rio de Janeiro, Academia Brasileira de Ciências, 2016.

[4] MACDONALD, J. R., Impedance spectroscopy emphasizing solid materials and systems, $1^{\mathrm{a}}$ ed., New York, Wiley, 1987.

[5] SOARES, A. B., SILVA, P. R. N., FREITAS, J.C.C., et al., "Estudo da oxidação total do etanol usando óxidos tipo perovskita (B= Mn, Ni, Fe)", Química Nova, v. 30, n.5 pp. 1061-1066, Julho 2007.

[6] LIMA, S.M., ASSAF, J. M., "Síntese e caracterização de perovskitas $\mathrm{LaNi}_{(1-\mathrm{x})} \mathrm{Co}_{\mathrm{x}} \mathrm{O}_{3}$ como precursores de catalisadores para a conversão do metano a gás de síntese pela reforma com $\mathrm{CO}_{2}$ ", Química Nova, v. 30, n.2, pp. 298-303, Novembro 2006.

[7] STATHOPOULOS, V.N., BELESSI, V.C., BAKAS, T.V., et al., "Comparative study of La-Sr-Fe-O perovskite-type oxides prepared by ceramic and surfactante methods over the $\mathrm{CH}_{4}$ and $\mathrm{H}_{2}$ lean-deNO $\mathrm{O}_{\mathrm{x}}$, Applied catalysis B: Environmental, v. 93, n. 1-2 ,pp. 1-11, Novembro 2009.

[8] IWAHARA, H., ESAKA, T., UCHIDA, H., et al., "Proton conduction in sintered oxides and its application to steam electrolysis for hydrogen production", Solid State Ionics, v. 3-4, n.1, pp. 359-363, Agosto 1981.

[9] KREUER, K.D., ADAMS, St., MUNCH, W., et al., "Proton conducting alkaline earth zirconates and titanates forhigh drain electrochemical applications", Solid State Ionics, v. 145, n. 1-4, pp. 295-306, Dezembro 2001.

[10] STEELE, B.C.H., HEINZEL, A., "Materials for fuel-cell technologies", Nature, v. 414, n.1, pp. 345-352, Novembro 2001.

[11] ZHAO, F., PENG, R., XIA, C., "A $\mathrm{La}_{0.6} \mathrm{Sr}_{0.4} \mathrm{CoO}_{3-}$ d-based electrode with high durability for intermediate temperature solid oxide fuel cells", Mater Res Bull, v. 43, n.2, pp. 370-376, Novembro 2008.

[12] MARTINS, T.S., HEWER, T. L. R., FREIRE, R. S. "Cério: propriedades catalíticas, aplicações tecnológicas e ambientais", Química Nova, v. 30, n. 8, pp. 2001-2006, Outubro de 2007.

[13] SANTOS, A.G., FONTES, F.A., SOUSE, J.F., et al., "Síntesis y refinado por el método Rietveld de la fase perovsquita obtenida a partir del método de co-precipitación vía oxalato", Información Tecnológica, v.22, n.1, pp. 17-28, Fevereiro 2011.

[14] NASCIMENTO, H.B.B.C., GODINHO, M.J., KIMINAMI, R.H.G.A., "Investigação da influência da dopagem de condutores protônicos de cerato de bário", The Journal of engineering and exact sciences, v. 3, n.8, pp. 1271-1279, Dezembro 2017.

[15] KNIGHT, K.S., BONANOS, N., "The crystal structures of some doped and undoped alkaline earth cerate perovskites", Mater. Res. Bull., v. 30, n.3, pp. 347-356, Março 1995.

[16] LEE, D.W., WON, J.H., SHIM, K.B., "Low temperature synthesis of $\mathrm{BaCeO}_{3}$ nano powders by the citrate process", Mater. Lett., v. 57, n.22-23, pp.3346-3351, Julho 2003.

[17] SANTOS, A.G., SILVA, R.R., DANTAS, A.G.O., et al., "Efeito do pH, Razão molar de EDTA: Ácido cítrico: íons metálicos totais e do tratamento térmico na obtenção da $\mathrm{BaCeO}_{3}$ com base no método de complexação EDTA-Citrato", Revista Verde, v. 9, n.4, pp. 149-161, Dezembro 2014.

[18] FU, Y.P., WENG, C.S., "Effect of rare-earth ions doped in $\mathrm{BaCeO}_{3}$ on chemical stability, mechanical properties, and conductivity properties", Ceram. Int., v. 40, n.7, pp.10793-10802, Agosto 2014.

[19] CHI, X., ZHANG, J., WU, M., et al., "Study on stability and electrical performance of yttrium and bismuth co-doped $\mathrm{BaCeO}_{3}$ ", Ceram. Int.,v. 39, n. 5, pp. 4899-4906, Julho 2013.

[20] KÖFERSTEIN, R., JÄGER, L., EBBINGHAUS, S.G., "Sintering of a fine-grained $\mathrm{BaCeO}_{3}$ powder obtained from a co-precipitation method", J. Mater. Sci. v. 45, n.23, pp. 6521-6527, Dezembro 2010.

[21] KÖFERSTEIN, HESSE, R., D., EBBINGHAUS, S.G., "Synthesis and characterization of a nano-scaled barium cerate perovskite powder using starch as polymerization agent", Solid State Ionics, v. 203, n.1, pp. 52-56, Novembro 2011. 
[22] LACORRE, P.,TORRANCE, J.B., PANNETIER, J., et al., "Synthesis, crystal structure, and properties of metallic $\mathrm{PrNiO}_{3}$ : Comparison with metallic $\mathrm{NdNiO} 3$ and semiconducting $\mathrm{SmNiO}_{3}$ ”, J. Solid State Chem., v. 91, n.2, pp. 225-237, Abril 1991.

[23] LOBATO, M.F., SANTOS, A.G., VITAL, A.B., et al., "Síntese do cerato de bário pelo método de complexação combinando EDTA-citrato e avaliação catalítica na oxidação do monóxido de carbono testada em reator de leito fixo", Cerâmica, v. 62, n. 363, pp. 288-293, Setembro 2016.

[24] LOPES, F.W.B., ARABB, M., MACEDO, H.P., et al., "High temperature conduction and methane conversion capability of $\mathrm{BaCeO}_{3}$ perovskite", Powder Technology, v.219, n.1, pp. 186-192, Março 2012.

[25] ZHU, X., YANG, W., Mixed Conducting Ceramic Membranes: Fundamentals Materials and Applications, $1^{a}$ ed., Berlin, Springer, 2017.

[26] DASHTI, A., ASGHARI, M., "Recent Progresses in Ceramic Hollow - Fiber Membranes", Chembioeng Reviews, v. 2, n.1, pp. 54-70, Fevereiro 2015.

[27] XIE, K., YAN, R., CHEN, X., et al., "A stable and easily sintering $\mathrm{BaCeO}_{3}$-based proton-conductive electrolyte”, Journal of Alloys and Compounds, v. 473, n.1-2, pp. 323-329, Abril 2009.

[28] BABILO, P., HAILE, S. M., "Enhanced sintering of yttrium-doped barium zirconate by addition of ZnO", Journal of the American Ceramic Society, v. 88, n.1, pp. 2362-2368, Maio 2005.

[29] GORBOVA, E., MARAGOU, V., MEDVEDEV, D., et al., "Influence of sintering additives of transition metals on the properties of gadolinium-doped barium cerate", Solid State Ionics, v. 179, n.21-26 pp. 887-890, 2008.

[30] COSTA, R., GRÜNBAUM, N., BERGER, M. H., et al., "On the use of $\mathrm{NiO}$ as sintering additive for $\mathrm{BaCe}_{0,9} \mathrm{Y}_{0,1} \mathrm{O}_{3-a}$ ", Solid State Ionics, v. 180, n.11-13, pp. 891-895, Junho 2009.

\section{ORCID}

Aliciane Cintia Maia Gama

André Luis Lopes Moriyama

Angélica Belchior Vital

Carlson Pereira de Souza https://orcid.org/0000-0003-1626-2091

https://orcid.org/0000-0001-7611-2074

https://orcid.org/0000-0003-3501-5379

https://orcid.org/0000-0003-0736-0394 